\title{
ORGANIZATIONAL AGILITY IN TURKEY: THE REMOTE WORK DURING THE CORONAVIRUS PANDEMIC
}

\author{
Aysel ARSLAN \\ Lecturer, Ondokuz Mayıs University, Health Services Vocational School, \\ E-Mail: aysel.arslan@omu.edu.tr, Samsun/Turkey ORCID NO: 0000-0002-4973-7957
}

\section{Çetin BEKTAŞ}

Prof. Dr. Tokat Gaziosmanpaşa University, Economics and Administrative Faculty, E-Mail: cetin.bektas@gop.edu.tr, Tokat/Turkey ORCID NO: 0000-0002-0078-3469 


\title{
ORGANIZATIONAL AGILITY IN TURKEY: THE REMOTE WORK DURING THE CORONAVIRUS PANDEMIC
}

\begin{abstract}
The struggle of businesses with emerging problems has been discussed several times in the literature; however, policies to continue production against epidemic diseases that can be among natural disasters have not been discussed much throughout the world until 2020. The coronavirus pandemic, which emerged all over the world in 2020, largely prevented the businesses from running. However, some enterprises have continued to run partially or fully remote under the pandemic process measures. Within the scope of business management, the global coronavirus (COVID-19) epidemic has created a vision for businesses to act quickly against the crisis and adapt themselves to the situation in case of extraordinary conditions. In this study, besides the importance of organizational agility in enterprises, how much the businesses in Turkey are ready for the global coronavirus (COVID-19) and how fast they start remote work will be discussed. At the same time, factors preventing remote work in organizations will be examined.
\end{abstract}

Keywords: Organization, Organizational Agility, Remote Work.

JEL Classification Codes: M1 


\section{INTRODUCTION}

Today, businesses have to improve and change themselves to adapt to the ever-changing environment. Studies on this subject show that successful companies are the ones that adapt to change fast. Companies have to keep up with various changes in political, economic, technological, social, and cultural fields. Enterprises with high competitiveness are those that believe in the necessity of change and are ready for it. Planned changes are essential for the achievement of organizational goals. Businesses may have to undergo some changes in a sudden and unplanned way. The important thing here is the speed and effect of the reactions of firms to these conditions that may suddenly arise. The concept of organizational agility has gained importance in the business world since the 1990s. Organizational agility means the prompt and correct responses of organizations to unexpected happenings and threats. For this, organizational agility must be supported by strategy and organizational competence. It is not enough for organizations to be physically ready for the desired rapid change, but also knowledge, skills, and desire of the staff must be provided to make this change. So, are organizations prepared for this unexpected change? While the answer to this question is "yes", this study will examine the speed and efforts of businesses in Turkey to work remote in the face of the 2020 global outbreak of coronavirus. This study aims to investigate organizations that work remotely with agility under the coronavirus measures in Turkey and to put forward solutions to the obstacles to manoeuvre. In this way, it is desirable to measure the effect of the response of organizations to situations that may arise suddenly. The study intends to guide businesses that are trying to adapt to changes. At the same time, it is hoped that this study will benefit the scientists working on this issue as it reveals the state of organizational agility in Turkey.

As the method of the study, one of the qualitative research methods, a case research design was used. The main objective of qualitative research is to provide a realistic and descriptive picture of the event or phenomenon in question as a result of the study (Gürbüz and Şahin, 2017: 409). In the study, document analysis method was used as a data collection tool. The survey data included in the course of Deloitte company titled "The Future of Work: Preserving the organizational durability in the remote working system" were examined. The content analysis method was used in the analysis of data. With the content analysis, the data that provide the concepts and relationships required for the research are examined in depth. The survey conducted by Deloitte was performed within 15 days of the announcement of the first COVID-19 case in Turkey. In the study conducted by the company, the surveys were carried out for participants from different sectors, departments, and cities to gather information about remote work. Since the survey was conducted after the first case of coronavirus appeared in Turkey, it was examined to show the agility of the organizations for this study shortly. Organizational agility requires rapid and immediate response to unexpected events resulting from changes and developments. In this study, organizations and sectors that managed to rush to remote work in the face of coronavirus in Turkey were examined. Besides, the factors that prevent remote work in Turkey have been identified, and solutions have been offered.

\section{ORGANIZATIONAL AGILITY}

Organizational agility is a remarkable and essential concept to keep up and survive the rapidly changing, turbulent market conditions in today's business world. Skill is not to be afraid of change, but to be fast and flexible in the face of change. Organizational agility is to create value by innovating in the product, production channels and market segmentation of the product offered by companies and increasing this value continuously. In this way, companies that have obtained competitive advantage always pursue opportunities in their market areas and collect the necessary information for this (Sambamurthy et al., 2003: 237). Organizations should encourage their employees to learn, develop and change quickly by creating strategic information to capture opportunities and maintain competitiveness in the face of growing threats. They must also organize all their other resources in the direction of continuous development and change. Organizational agility is a set of values that give organizations an advantage, showing how competitive they are. The winning organizations in the global market are those that can respond to internal and external factors on time, provide fast and flexible product innovation, and have the ability to effectively coordinate and reorganize their internal and external activities. There are two fundamental dimensions of sustainability in organizations. The 
first is to acknowledge that the environment has changing, dynamic properties. The second is the emphasis on the crucial role of strategic management of organizations in the face of this change. In this way, changes in internal and external factors are adapted, integrated, and restructured in the organization (Lenssen and Smith, 2019: 1-5). The increasing prevalence of social media and webbased services in the 21 st century demands to respond rapidly to customer demands and needs, to be agile and flexible. The dimensions of organizational agility can be addressed in four groups as speed, ability to respond to changing customer demands, flexibility, and competence. The speed dimension is determined by the rate with which the organization conducts its activities, solves problems, assesses opportunities, adapts to a new situation, and makes decisions.

The size of responding to changing customer demands is that the organization can anticipate changes in the external environment and has proactive measures ready to respond to these changes in a reactive manner. In this way, growth is affected positively by turning it into opportunity, without being harmed. The flexibility dimension is the continuous regulation of the organization's structure and processes according to the changes occurring in the external environment. Competence dimension is the ability and power to provide efficiency, effectiveness, and competence as well as the realization of the organization's goals and objectives (İnanır, 2020: 73). Organizational agility manifests itself with reactions to unexpected and sudden events as well as to ordinary or planned changes in the face of organizational developments. Organizations that respond to change correctly and are prepared to develop these abilities over time and strengthen their state of being agile. Reacting quickly to change organizationally requires being flexible in working life as well.

\section{FLEXIBLE WORKING MODELS}

Flexible working models are a current topic discussed in all countries of the world with globalization. Today, three points of view stand out in discussing flexible working models of organizations: The first point of view highlights how the Just in Time (JIT) system drives changes in organizations, which requires a workforce that can respond quickly to technological and market fluctuations. In the face of increasingly specialized products produced On-Demand, businesses need to adjust the size and location of their workforce. In this context, communication and transportation technologies have facilitated the flexible position of production so that customers can take advantage of the specific skill or wage characteristics of local labour markets. The centralization and geographical distribution of production have led to the proliferation of smaller production units that previously supplied goods and services that were only produced by one business. The second approach to flexibility stems from the increasing competitiveness of the global economy, which leads businesses to look for ways to reduce labour costs and increase labour productivity. In addition to restructuring external labour markets through strategies such as downsizing, outsourcing, or subcontracting, businesses are looking for new ways to improve remaining internal labour productivity. In the model presented for organizational restructuring, the organization consists of a small and stable "core" structure of the senior management professional and a much larger, more flexible and lower cost "environment" structure. The third perspective highlights the political nature of flexibility, which is seen as a struggle over whether governments, businesses, or workers will benefit from changes in the regulation, organization, and wage distribution of labour markets (Eyck, 2003:1). Within the framework of all these factors, many organizations implement flexible working methods that suit them. Flexible working models include teleworking, working from home, fixed-term work, part-time work, on-call work, sub-contracting (subcontracting), loan work, compressed week work, temporary work (periodic work), job sharing ( job-sharing), shift work, short work, overwork, and compensatory work.(Tilev, 2018: 128). According to some opinions, flexibility in working life is presented as a primary tool for increasing employment in terms of spreading social welfare. It is therefore seen as an essential element in the adaptation of states to the new economy. According to the opposing view, flexibility in working life is seen as an element of globalized capitalism. This element is destroying labour markets and organizations (Zengingönül, 2003:158).

One of the most significant changes brought about by information and communication technologies with globalization is that employees can work anywhere and at any time. As of March 2020 , employees are working with information and communication technology tools from anywhere 
they want, including home, in the remote work model, where organizations are transitioning quickly under coronavirus measures. Through communication services, production is maintained outside of traditional workplaces. Today, remote work is the use of information technologies in part or whole, and the daily work carried out in the workplace is done in different places. Remote work can be done from home or anywhere on the move. In this way, the rate of implementation of remote work is increasing rapidly all over the world. Many developed countries around the globe implement small operations at various speeds. Remote work is a flexible way of working that directly or indirectly affects working life (Alkan Meşhur, 2007: 265). Some organizations adopt and implement this way of working, while others do when needed remotely.

\section{AGILE ORGANIZATIONS IN TURKEY IN THE FACE OF CORONAVIRUS}

In the face of the coronavirus (COVID 19) outbreak that threatens the world in 2020, businesses have had to take several measures to prevent the transmission and spread of the disease to their domestic and international customers. For this reason, some companies have had to break from continuing their production activities in the workplace. To determine how well-prepared organizations are for the global outbreak of coronavirus in Turkey, Deloitte researched within 15 days of the announcement of the first COVID-19 case in Turkey in 2020. The survey was conducted with 334 participants from 17 different cities in Turkey, with $71.7 \%$ from Istanbul and $28.3 \%$ from other towns (Deloitte, 2020). The sectors involved in the research are shown in Table 1.

Table 1. Sectors participating in the Remote Work System survey for the COVID-19 outbreak

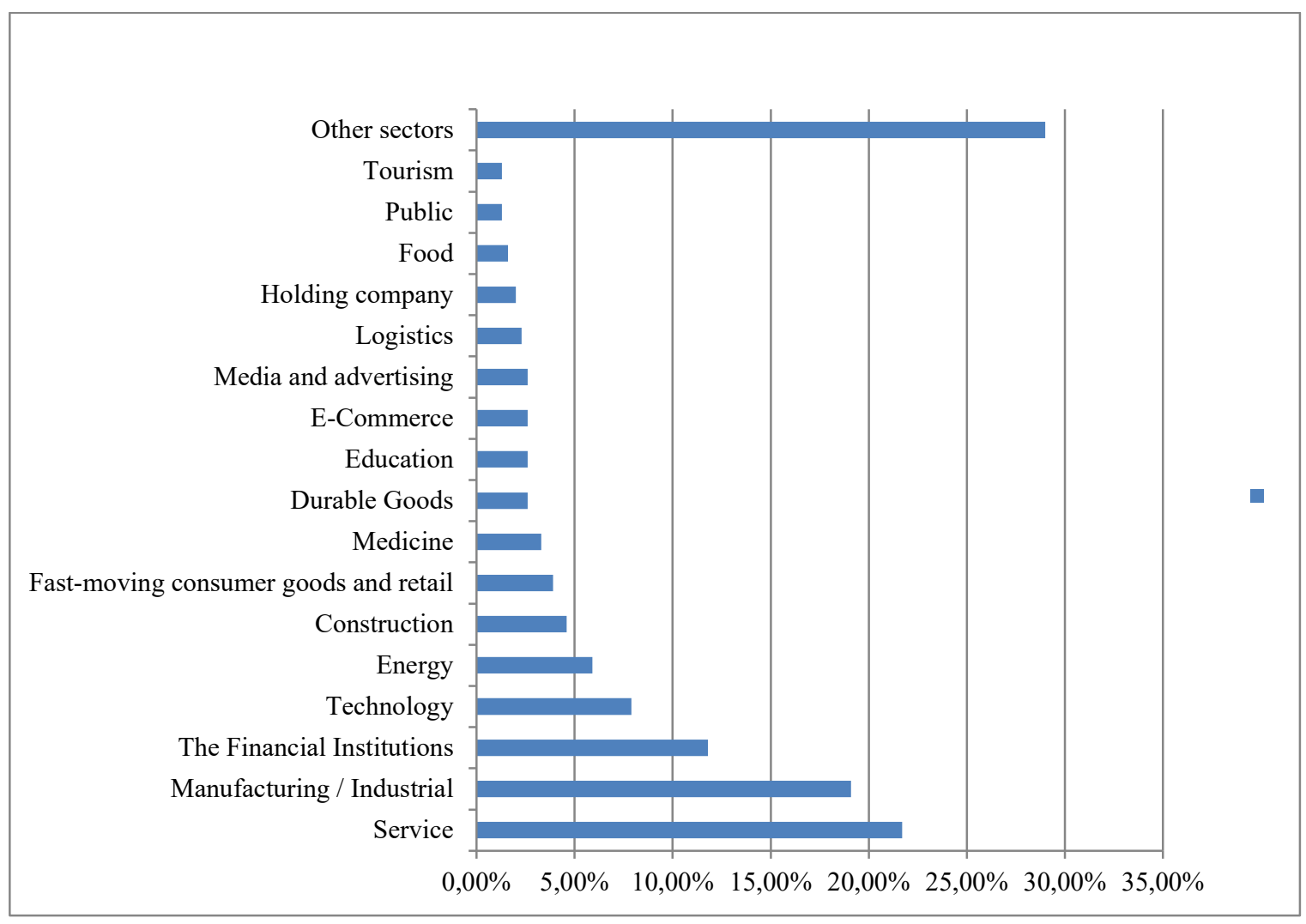

Source: Compiled by the authors from Deloitte 2020 data.

To determine how much organizations in Turkey are ready for working remotely under coronavirus measures, as the first question in the survey, Deloitte firm sought an answer to the question "Have you started homeworking?" The results are shown in Figure 1 below. 
Figure 1. The transition of Participants to Homeworking

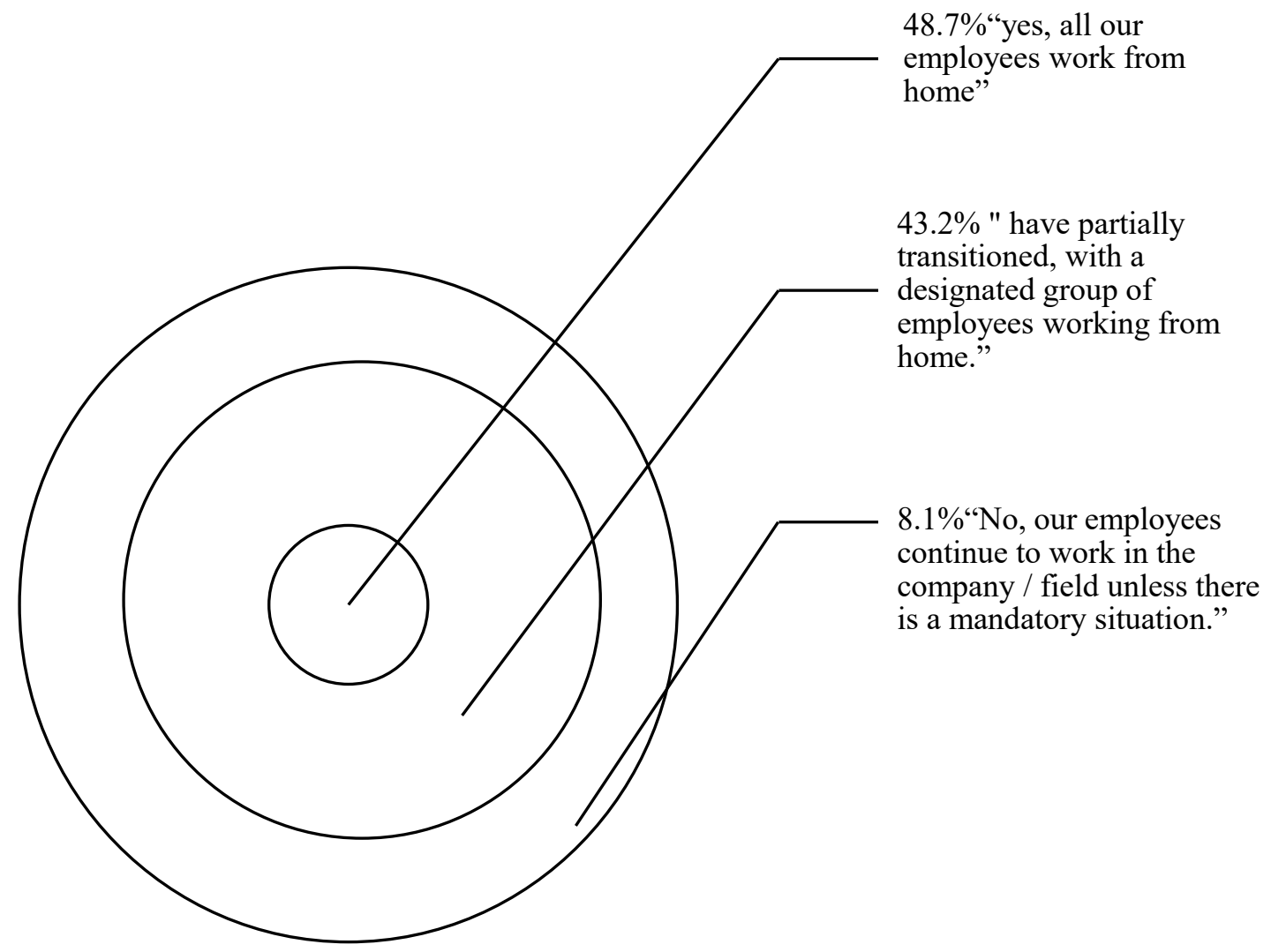

Source: Compiled by the authors from Deloitte 2020 data.

When Figure 2 was examined, $48.7 \%$ of the 334 companies that participated in the survey, namely 163 companies, started working from home to protect their domestic and international customers from the outbreak within the first 15 days when coronavirus appeared. $43.2 \%$ of the participants, i.e. 144 companies started working from home with a designated group of employees, and partially switched to working from home. Twenty-seven firms, $8.1 \%$ of the surveyed firms, stated that they continue to use in the company/ field (Deloitte, 2020). The distribution of companies starting to work from home in Istanbul and other cities is as follows in Figure 2.' and is shown in Figure 3.

Figure 2. The transition of Participants in Istanbul to Work from Home 


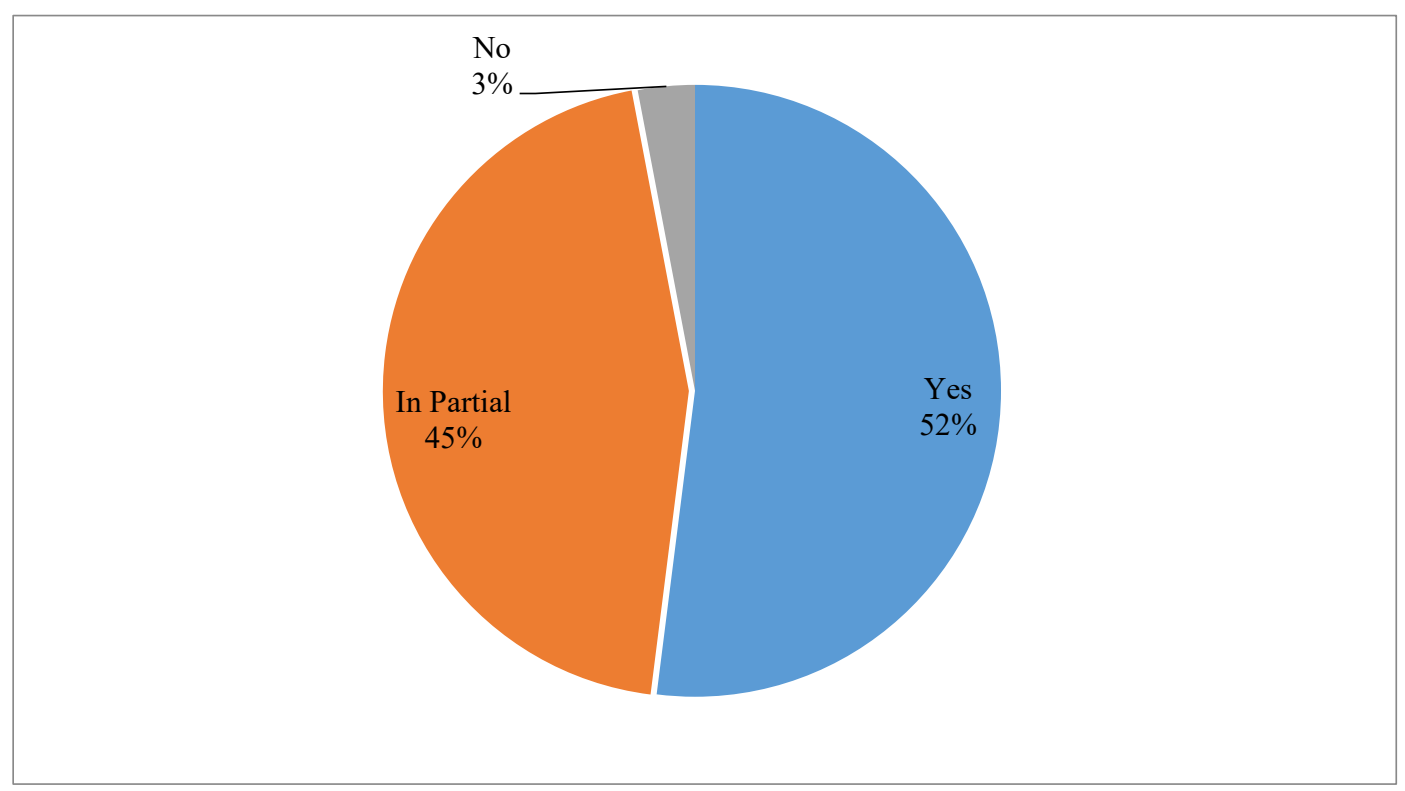

Source: Compiled by the authors from Deloitte 2020 data.

Figure 3. Transition Of Participants Outside Istanbul To Work From Home

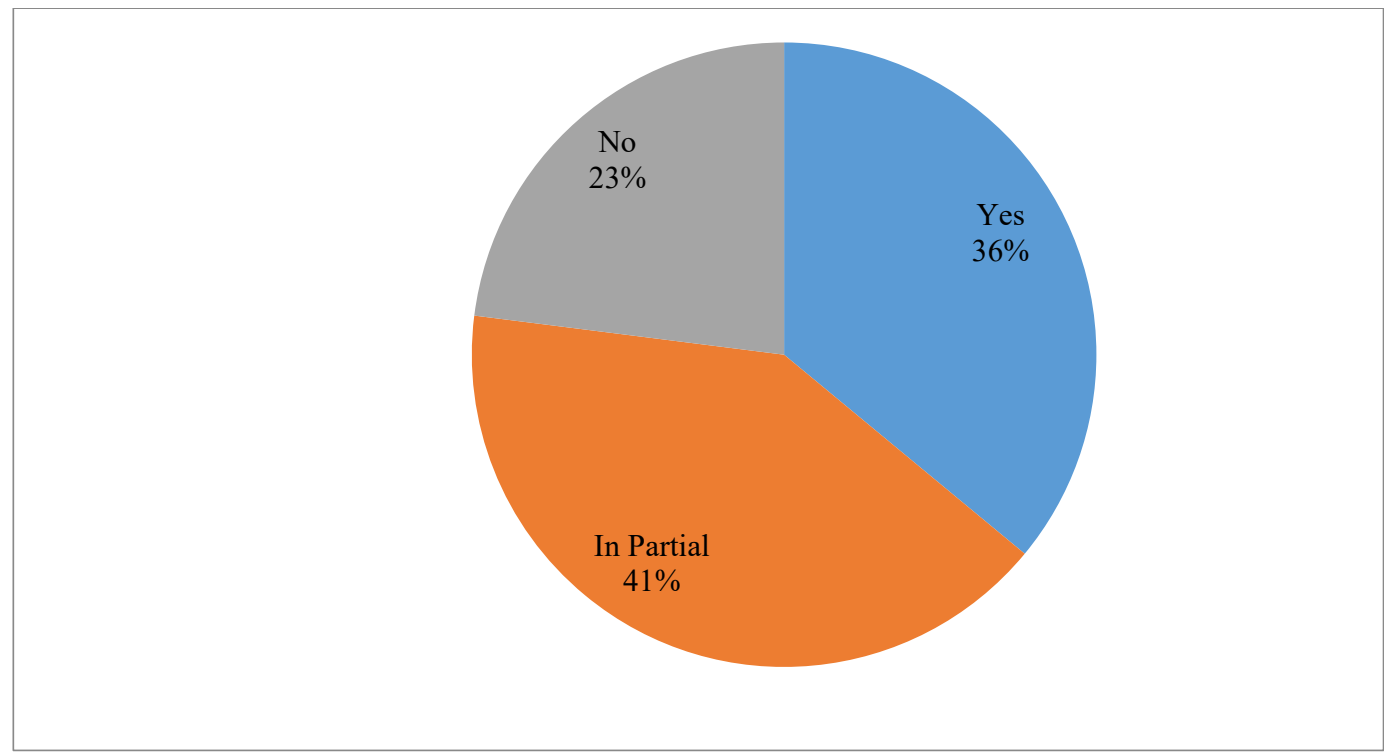

Source: Compiled by the authors from Deloitte 2020 data.

When Figure 2 and Figure 3 are examined, it is observed that the transition to fully remote work is $16 \%$ more in Istanbul than in other provinces. Likewise, the partial change to remote work is $4 \%$ higher in Istanbul than in other regions. Companies that do not switch to working are $20 \%$ more likely in other cities than in Istanbul remotely. 
Table 2. Types of Business Life of Firms on A Sectional Basis.

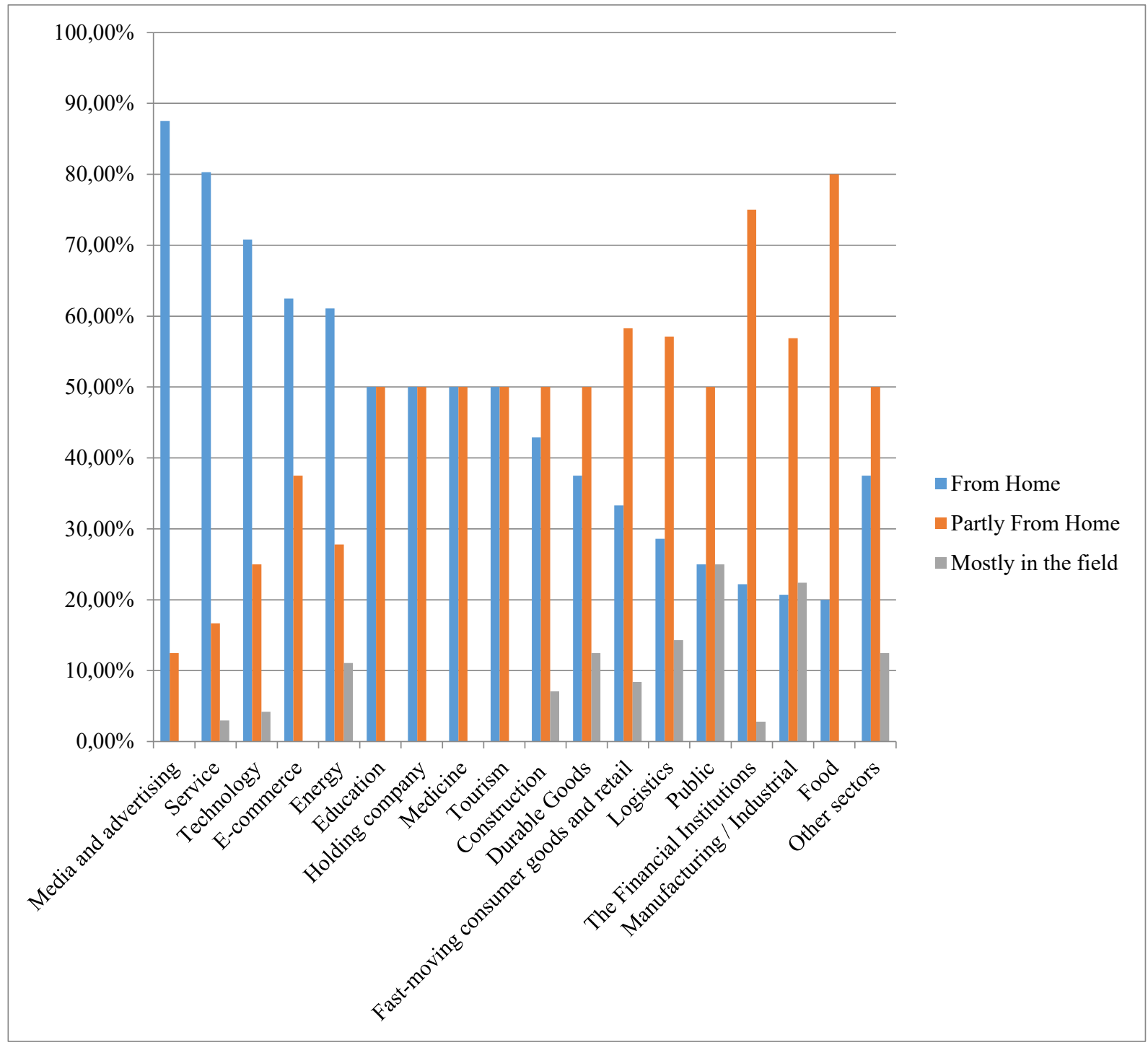

Source: Compiled by the authors from Deloitte 2020 data.

In Table 2, indicators are given for companies to maintain their business life from home, partly from home and mostly in the field. As it can be understood from Table 2, the media and advertising sector, with a rate of $87.5 \%$, are the leading sectors that have quickly switched to the remote working system with all their employees. This sector is followed by the service sector, with a rate of $80.3 \%$. Technology with $70.8 \%$ and e-commerce with $62.5 \%$ are the leading sectors in the transition to remote work. The food sector, with $80 \%$, and financial institutions, with $75 \%$, are at the top of the industries that have made the part-time transition to working remotely. While manufacturing and industrial sectors were among the sectors that had the most difficulty in making the transition to remote work, the public sector also seems to have continued to work mainly in the office or workplace. Deloitte's survey of the sectors to work remotely to reveal the factors that are forced to work from home " what is the most difficult for your company?" the answer to the question was $43 \%$ culture and habits. This result was followed by customer expectations of $20 \%$ and the organizational 
structure of the same $20 \%$. By $17 \%$, technology infrastructure was considered a challenge (Deloitte, 2020). These ratios are shown in Figure 4 below.

Figure 4. Issues Forcing Companies To Work From Home

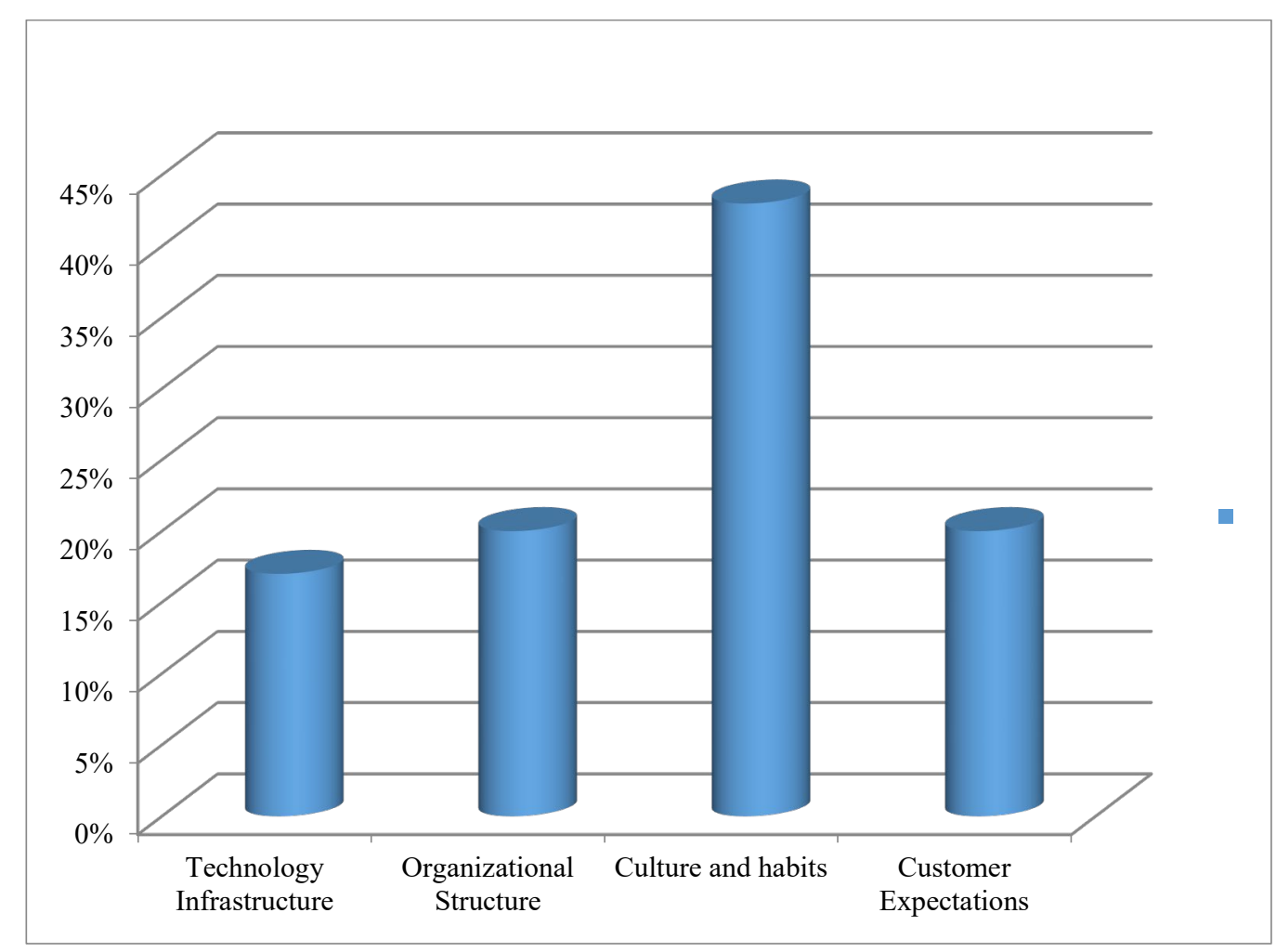

Source: Compiled by the authors from Deloitte 2020 data.

\section{CONCLUSION AND RECOMMENDATIONS}

Organizations have to adapt to the dynamic environment in which they live to gain a sustainable competitive advantage in their working life. In the face of increasing uncertainty in the business world, it is not enough to achieve success in day-to-day activities. Organizational success requires being ready for what can be experienced by anticipating the threats and opportunities in the environment. Today, many organizations follow these changes and developments closely and prepare themselves for the future. In this context, organizational agility is the power of institutions to adapt quickly to the changing environment, and therefore to be prepared for threats and to be able to turn opportunities into advantages.

The December March 2019 outbreak of the disease coronavirus (COVID-19) in Wuhan, China, developed into an explosion and the first case in Turkey emerged in March 2020. As in the whole world, many measures have been taken in Turkey to combat this global epidemic. Hygiene rules such as the use of masks, washing hands frequently, and cleaning with disinfectant agents, disinfection of the contact surfaces have started to be applied to prevent infection. Besides, it was necessary to comply with the social distance rule, which says that at least 1,5-2 meters should be placed between two people. In organizational life, it has been not easy to put social distance between too many employees and those working in manufacturing businesses. In the face of the unexpected 
global outbreak coronavirus, many companies have switched to remote work since March 11, 2020, the date of the first case to appear in Turkey. In this study, companies, and sectors that started working remotely within the early 15 days of March 11, 2020, were examined, and factors that prevented working were evaluated remotely. In this study benefited from the survey data that Deloitte firm has made in this opinion. According to the data obtained, $48.7 \%$ of 334 businesses in Turkey switched to remote work, while $43.2 \%$ partial transition, $8.1 \%$ continued to work in the field. This finding shows that $91.9 \%$ of the businesses surveyed (entirely or partly by remote working model) are rapidly adapting to the changing situation. While companies in Istanbul respond quickly to the changing situation at a rate of $97 \%$, in cities outside Istanbul, this rate of change is $77 \%$.

Within the scope of coronavirus measures, advanced information, and communication technology products have enabled many businesses to conduct their activities remotely. However, due to the production characteristics of enterprises, the transition rates to remote operation may be different. The enterprises that could not make production without personnel went into part-time production and kept a small group of personnel in the field and continued production with the measures taken. The study found that $43 \%$ of the factors that force businesses to work from home were culture and habits. The other two factors are organizational structure with the same ratio $(20 \%)$ and customer expectations. At $17 \%$, there were problems with technology infrastructure. While it is pleasing that the issues related to technology infrastructure are at a minimum level, organizational culture is the most challenging factor, requiring changes in organizational thinking and behaviour. As a part of the classical organization work, work at work during working hours is left aside, flexible work should be supported by organizational culture, and positive interaction of organizational culture with environmental changes and developments should be ensured. We can express organizational culture as the beliefs, values, expectations, and the way the work is done that determine the behaviour of the employees in the organization. It should be accepted that the way work is done in organizations should move away from the Traditionalist understanding and that what is essential in organizations is that work is done more effectively and efficiently than where it is done. This factor is a fundamental feature that distinguishes one organization from another, and it is an essential part of organizational culture. It also allows the organization to act more flexibly under all circumstances. Today, for organizational success, organizational culture should be dominated by the idea that 'what is important in the success of the work is not the place where the work is performed, it is the efficient and effective realization'. Working with this process, instead of spending an inefficient work in the workplace, he can work efficiently in a place where he will both do his job and feel comfortable. Another factor that prevents remote work is organizational structure. The transformation of organizations from the hierarchical structure to more flexible project-type structuring or matrix structuring will support the tiny working model. Another factor is customer expectations. In a changing society, customer expectations also change over time. Classic Customer Relationship Management has been replaced by a management approach that meets customer expectations instantly and keeps pace with change quickly. However, organizations need to create the technological infrastructure suitable for remote operation and train their employees to use these technologies and follow technological innovations.

\section{REFERENCES}

Alkan Meşhur, F. H. (2007). Geleceğin Çalışma Biçimi Tele Çalışmaya İlişkin Yaklaşımlar. Akademik Bilişim, 7(09), 265-272.

Deloitte. (2020). İşin Geleceği: Uzaktan çalışma sisteminde organizasyonel dayanıklılı̆̆ı korumak. Erişim adresi: www2.deloitte.com.

Eyck, K. Van (2003). Flexibilizing Employment: An Overview. International Labour Organization, Genova.

Gürbüz, S., Şahin, F. (2017). Sosyal Bilimlerde Araştırma Yöntemleri Felsefe-Yöntem-Analiz, Ankara: Seçkin Yayınevi. 
İnanır, A. (2020). Modern İşletmecilikte Yönetsel Konular. Sağır. M (Ed.), Örgütsel Çeviklik içinde (s.73). Eğitim Yayınevi: Konya.

Koç, M., Görücü, İ. (2011). 4857 Sayılı İş Kanunu'na Göre Kısmi Çalışma Uygulaması ve Sonuçları. Çalışma ve Toplum, 1 (28), 149-178.

Lenssen, G. G., Smith, N.C. (2019). Managing Sustainable Business: An Executive Education Case and Textbook. Springer: Singapore.

Sambamurthy V., Bharadwaj A., Grover V. (2003). Shaping Agility through Digital Options: Reconceptualizing the Role of İnformation Technology in Contemporary Firms. MIS Quarterly, 27 (2), 237-263.

Tilev, F. (2018). Esnek Çalışma ve Kadın İstihdamı. Fırat Üniversitesi İ̈BF Uluslararası İktisadi ve İdari Bilimler Dergisi, 2 (2), 121-150.

Zengingönül, O. (2003). Sosyal Politika-Esnek Çalışma Biçimleri Paradoksunda Avrupa Birliği. Dokuz Eylül Üniversitesi Sosyal Bilimler Enstitüsü Dergisi, 5 (4), 157-171. 